\title{
Extinction of Cocaine Self-Administration Produces a Differential Time-Related Regulation of Proenkephalin Gene Expression in Rat Brain
}

José A. Crespo, M.Sc., Jorge Manzanares, Ph.D., José M. Oliva, M.Sc., Javier Corchero, Ph.D., Tomás Palomo, M.D., Ph.D., and Emilio Ambrosio, Ph.D.

The purpose of this study was to examine the time course effects of extinction of cocaine self-administration behavior on proenkephalin (PENK) gene expression in caudateputamen nucleus (ST), nucleus accumbens (Acc), olfactory tubercle (Tu), piriform cortex (Pir), ventromedial hypothalamic nucleus (VMN), and central amygdala (Ce) as measured by in situ hybridization histochemistry. Seventy-two littermate male Lewis rats were randomly assigned in triads to one of three conditions: (1) contingent intravenous self-administration of $1 \mathrm{mg} / \mathrm{kg} /$ injection of cocaine (CONT); (2) noncontingent injections of either 1 $\mathrm{mg} / \mathrm{kg} /$ injection of cocaine (NONCONT); or (3) saline yoked (SALINE) to the intake of the self-administering subject. The self-administering rats were trained to selfadminister cocaine under a FR5 schedule of reinforcement for a minimum of 3 weeks. After stable baseline levels of drug intake had been reached, saline was substituted for drug. Following this first extinction period, cocaine selfadministration was reinstated for an additional period of 2 weeks. Immediately after cessation of the last session of cocaine self-administration (day 0) and 1-, 5-, and 10-day after the second extinction period, animal brains in each triad were removed to be processed for in situ hybridization. PENK $m$ RNA levels were significantly higher in the cocaine groups when compared with SALINE group in the ST, Acc, Pir, and Tu regions on days 0, 1, 5, and 10 of the extinction and lower in the Ce region of CONT group when compared to NONCONT and SALINE groups on days 1, 5, and 10 of the extinction period. In the VMN nucleus, PENK mRNA content in CONT group versus NONCONT and SALINE groups was also lower, but there were statistically significant differences only on day 5 .

These results suggest that changes in PENK gene expression after contingent cocaine administration might be involved in cocaine withdrawal states.

[Neuropsychopharmacology 25:185-194, 2001] (C) 2001 American College of Neuropsychopharmacology. Published by Elsevier Science Inc.
From the Departamento de Psicobiología (JAC, JMO, EA), Facultad de Psicología, Universidad Nacional de Educación a Distancia (UNED), Madrid, Spain; Servicio de Psiquiatría (JM, TP), Hospital Doce de Octubre, Madrid, Spain; and Laboratory of Metabolism (JC), Division of Basic Sciences, National Cancer Institute, Bethesda, Maryland.

Address correspondence to: Jorge Manzanares, Ph.D., Servicio de Psiquiatría, Hospital Doce de Octubre, Av. Córdoba s/n 28041 Madrid, Spain. Tel.: 34-91-390 8022; Fax: 34-91-390 8538; E-mail: jorgemr@eucmax.sim.ucm.es

Received August 18, 2000; revised December 19, 2000; accepted December 21, 2000.
KEY WORDS: Extinction; Cocaine self-administration; Proenkephalin mRNA; Gene expression; Withdrawal

Cocaine abuse and dependence remain major public health and social problems. Cocaine abuse results from a complex interplay of behavioral, pharmacological, and neurobiological determinants. The main pharmacological effect of cocaine is to inhibit the reuptake of monoamines dopamine, norepinephrine, and serotonin at presynaptic terminals. As a consequence of these ac- 
tions, cocaine potentiates neurotransmission of all three monoamines (Hadfield et al. 1980; Heikkila et al. 1975; Ross and Renyi 1969). The major behavioral effect of cocaine is a psychomotor stimulant action with reinforcing addictive properties. This behavioral effect is produced primarily by inhibition of dopamine uptake, thereby increasing extracellular concentrations of released dopamine (Ritz et al. 1987; for a review see Kuhar et al. 1991; Spanagel and Weiss 1999). However, a recent study using mice lacking dopamine transporter proposed other mechanisms, such as increases in serotonin transmission, may mediate the reinforcing effects of cocaine (Rocha et al. 1998).

Several studies have shown that cocaine also affects the expression of opioid peptides and opioid receptors. For example, chronic cocaine administration leads to increases in circulating $\beta$-endorphin levels (Moldow and Fischman 1987), striatal preprodynorphin mRNA levels (Hurd et al. 1992; Daunais et al. 1993; Daunais and McGinty, 1995; Spangler et al. 1993, 1996, 1997), and striatonigral dynorphin content (Sivam 1989; Smiley et al. 1990) in rats and to decreases in preproenkephalin mRNA levels in rhesus monkeys (Daunais et al. 1997) and humans (Hurd and Herkenham 1993). Repeated administration of cocaine can also regulate the activity of opioid receptors in discrete brain regions of rats. Indeed, it has been shown that 2 weeks of either continuous administration of cocaine via subcutaneously implanted osmotic mini-pumps (Hammer 1989) or repeated daily injections (Unterwald et al. 1992, 1994) lead to increase in $\mu$ and $\kappa$-opioid receptor density in terminal fields of the nigrostriatal and mesolimbic-mesocortical dopamine systems (for a review see Izenwasser 1998).

Identification of the alterations in brain function by chronic cocaine administration has been a focus of many research efforts over the last two decades (for review see Nestler 1993; White et al. 1995; Pierce and Kalivas 1997). This effort has consistently revealed the induction of many changes in cellular processes, although the data sometimes appear contradictory. Some of the discrepancies found on neuroadaptations to cocaine administration may be related to differences in the duration of the treatment, dosage of cocaine administered, time after the last drug administration, or the animal model employed. In this respect, the majority of studies investigating cocaine-induced cellular neuroadaptations use repeated noncontingent administration of this drug; whereas, fewer studies employ drug selfadministration. However, long-term neuroadaptations to chronic cocaine administration could arise not only from the pharmacological actions of cocaine on neurotransmitter systems but also by an interaction between this pharmacological action and the animal's environment (Dworkin et al. 1992, 1995; Wilson et al. 1994; Hemby et al. 1997). Indeed, it has been suggested that in humans the classical conditioning of the pharmaco- logical actions of cocaine with environmental stimuli plays an important role in long-term addictive potential of this drug and in the liability to relapse in recovering cocaine addicts (Ehrman et al. 1992).

The purpose of the present study was to examine the time course effects in proenkephalin (PENK) gene expression after cocaine self-administration and its extinction using a yoked-box procedure. This behavioral experimental design involves the use of triads to assess relative differences related to contingent versus noncontingent presentations of environmental events (Smith and Dworkin 1986). PENK mRNA levels were measured by in situ hybridization histochemistry in several rat brain regions immediately after the last day of cocaine self-administration and 1,5, and 10 days after extinction.

\section{MATERIALS AND METHODS}

\section{Animals}

Adult male Lewis rats (CRIFFA, France) weighing approximately $300-350 \mathrm{~g}$ at the beginning of their training were used. All animals were experimentally naive, housed individually in a temperature-controlled room $\left(23^{\circ} \mathrm{C}\right)$ with a 12 -h light-dark cycle $(08: 00-20: 00$ lights on), and given free access to Purina laboratory chow and tap water before initiation of the experiments. Animals used in this study were maintained in facilities according to European Union Laboratory Animal Care Rules.

\section{Surgery}

Experimentally naive subjects were surgically prepared with an IV catheter placed in the jugular vein. Polyvinylchloride tubing $(0.064$ i.d.) was implanted in the right jugular vein approximately at the level of the atrium under ketamine and diazepam anesthesia. The catheter was passed SC and exited in the midscapular region. The catheter then passed through a spring tether system (Alice King, Chatham, MA) mounted to the skull of the rat with dental cement. All subjects were housed individually following surgery and given at least 7 days to recover.

\section{Apparatus}

Twelve operant chambers (Coulburn Instruments, Allentown, PA, USA) were used for cocaine self-administration studies. Two levers designed to register a response when $3.0 \mathrm{~g}$ of force was applied were placed 14 $\mathrm{cm}$ apart on the front wall of the chamber. A microliter injection pump (Harvard 22) was used to deliver IV saline or drug injections to the rat. Drug delivery, operant data acquisition, and storage were accomplished on IBM computers (Med Associates, USA). 


\section{Experimental Procedure}

Cocaine-reinforced behavior was studied according to a procedure described previously (Ambrosio et al.1996). Briefly, before surgical implantation of the IV catheter, animals were trained to lever press for food reinforcement under a fixed ratio (FR) 5 schedule of reinforcement. Initially, a single lever press on the left-hand lever resulted in delivery of a food pellet $(45 \mathrm{mg}$, P.J. Noyes Company, Lancaster, NH, USA) and turned on a stimulus light above the lever. After responding was initiated, the response requirement to food delivery was raised in increments to 5, and a programmed 30-s time-out (TO) period in which responses had no programmed consequences followed each food pellet delivery (FR5:TO $30 \mathrm{~s}$ ). When behavior was maintained under the FR5 schedule of food-reinforced behavior, the catheter was surgically implanted as described.

After the post-operative period, 72 litter mate male Lewis rats were randomly assigned in triads to one of three conditions: (1) contingent IV self-administration of $1 \mathrm{mg} / \mathrm{kg} /$ injection of cocaine (CONT); (2) noncontingent IV injections of either $1 \mathrm{mg} / \mathrm{kg}$ of cocaine (NONCONT); or (3) saline (SALINE) yoked to the intake of the self-administering subject. Initially, substitution of food delivery by cocaine began under a FR1 schedule of reinforcement and was subsequently raised to FR5. In this case, a programmed 30-s time out in which responses had no programmed consequences followed each cocaine injection (FR5:TO $30 \mathrm{~s}$ ). Animals were allowed to self-administer cocaine in daily 2 -h sessions between 9:00 and 14:00 h, 7 days a week for a minimum of 3 weeks. After stable behavior was established (less than $10 \%$ of variability in the number of injections for 5 sequential days), saline was substituted for a minimum of 3 days in the operant chambers. After this first extinction period, cocaine self-administration behavior was reinstated and maintained for an additional minimum period of 2 weeks. Saline substitution was carried out again for 1,5, and 10 days in the operant chambers. Immediately after the last day of cocaine self-administration in which the animals reached the stability criterion (DAY 0) and after 1-day (DAY 1), 5-day (DAY 5), and 10-day (DAY 10) period of extinction, animal brains of each triad were removed to be processed for ISHH. Subjects in each group of triads was $18(\mathrm{CONT}=6$; NONCONT $=6$ : SALINE $=6$ ), and the total amount of brains removed was 72 [4 groups of triads (DAY 0, DAY 1, DAY 5, and DAY 10) $\times 18]$.

\section{In Situ Hybridization Histochemistry (ISHH)}

Brain sections were cut at $20 \mu \mathrm{m}$ at three different levels (six slides/level; two sections/slide) containing the brain regions of interest (ROIs). The first level includes nucleus accumbens (Acc), caudate putamen (ST), piri- form cortex (Pir), and olfactory tubercle (Tu). The second level contains central amygdala (Ce), and the third level contains ventromedial hypothalamic nucleus (VMN). All these sections were obtained according to Paxinos and Watson Atlas (Paxinos and Watson 1986)[/ RREFOL], mounted onto gelatin-coated slides and stored at $-80^{\circ} \mathrm{C}$ until the day of the assay.

ISHH was performed as described previously (Young et al. 1986) using synthetic 48-bases oligonucleotide probes complementary to PENK (NEN-Dupont, NEP502, Madrid, Spain). The oligonucleotide probe was labeled using terminal deoxytransferase (Boehringer, Madrid, Spain) to add a ${ }^{35}$ S-labeled deoxyATP (1000 Ci $\mathrm{mmol}^{-1}$; Amersham, Madrid, Spain) tail to the $3^{\prime}$ end of the probes. The probe (in $50 \mu \mathrm{l}$ of hybridization buffer) was applied to each section and left overnight at $37^{\circ} \mathrm{C}$ for hybridization. Following hybridization, sections were washed four times for $15 \mathrm{~min}$ each in $0.15 \mathrm{M} \mathrm{NaCl}, 0.015$ M sodium citrate, pH 7.2 (1X saline sodium citrate, SSC) at $55^{\circ} \mathrm{C}$, followed by two $30-\mathrm{min}$ washes in $1 \mathrm{X}$ SSC at room temperature, one brief water dip, and were then blown dry with air. Slides from all experimental groups were classified in three sets (each one corresponding to a different level of brain sectioning and containing the areas of interest). To control for imaging enhancement variables, each set of slides was apposed to the same film (Kodak BioMax MR-1, Amersham, Madrid, Spain) in individualized cassetes 3 days for the level containing Acc, ST, Pir, and Tu 7 days for the level containing VMN and 14 days for the level containing Ce.

Two slides per level (two slices/slide; two measurements/slice) in each animal were analyzed with a Macintosh computer using the public domain NIH Image program (developed at the U.S. National Institutes of Health and available on the Internet at http://rsb. info.nih.gov/nih-image). Brain regions positive for PENK mRNA hybridization were identified according to the previous reported PENK mRNA distribution in the rat brain (Harlan et al. 1987). Previous experiments in our laboratory have found that the selected times of exposure to film, in these brain regions, and under our experimental conditions (oligonucleotide probe, radioactivity added to each slide, incubation conditions, type of film selected), renders a hybridization signal whose gray levels are linear with the optical density, according to the NIH Image Program. Therefore, optical densities were calculated from the uncalibrated mode of the Image Program by subtracting from each measurement its corresponding background and expressed in gray-scale values. The background measurement was taken from an area of the slice with the lowest nonspecific hybridization signal and subtracted from the hybridization signal measurement in the same slice. Measurements were pooled from brain sections, and the values were averaged. Results were presented considering mean control values as $100 \%$. 
Additional brain sections were cohybridized with a 100-fold excess of cold probes or with RNAse to assert the specificity of the signal. As expected, no hybridization signal was detected in these sections (data not shown).

\section{Statistical Analyses}

The analysis of the PENK gene expression data was performed using a two-way analysis of variance (ANOVA) with the type of cocaine administration (CONT, NONCONT, or SALINE) serving as one independent variable and the brain area serving as the other independent variable. Subsequently, a one-way ANOVA followed by Student-Newman-Keul's test was performed for each brain region and day of extinction $(0,1$, 5 , and 10), with the type of cocaine administration (CONT, NONCONT, or SALINE) serving as independent variables. Differences were considered significant if the probability of error was less than $5 \%$.

\section{RESULTS}

In Figure 1, we present the behavioral data of the contingent, noncontingent, and saline groups used in our study. These data really represent responding of the contingent group only, because the noncontingent and saline groups did not have the possibility of responding: in both groups the subjects received cocaine (1 mg/ $\mathrm{kg}$ /injection) or saline passively; whereas, the contingent animals were able to self-administer the drug. In Figure 1, the behavioral data presented are divided in four consecutive phases. Phase 1 corresponds to acquisition and maintenance of cocaine IV self-administration behavior; phase 2 to first extinction of cocaine IV self-administration behavior; phase 3 to re-acquisition ; and phase 4 to second extinction. The data depicted in Figure 1 clearly show that cocaine maintained robust responding, as compared to the responding observed with saline (first and second extinction phases). The last 15 days of phase 1 (acquisition and maintenance) were very similar to the 15 days of phase 3 (re-acquisition). In
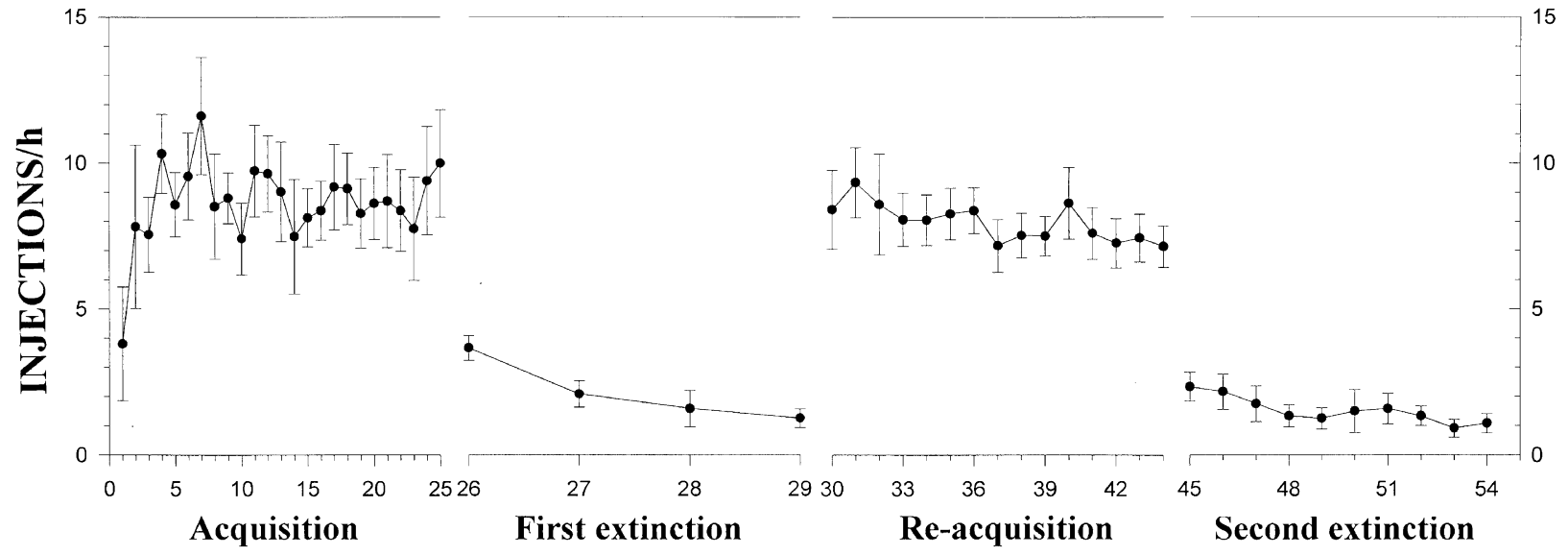

SESSIONS

Figure 1. Cocaine self-administration behavior and its extinction in contingent, noncontingent, and saline groups. The behavioral data correspond to the responding of cocaine $(1 \mathrm{mg} / \mathrm{kg} /$ infusion $)$ contingent self-administering animals, because noncontingent and saline subjects received passively cocaine $(1 \mathrm{mg} / \mathrm{kg} /$ infusion $)$ or saline when the contingent animals self-administer. The behavioral responses are presented divided in four consecutive phases: phase 1 corresponds to the acquisition and maintenance of cocaine IV self-administration behavior; phase 2 to the first extinction of cocaine IV selfadministration behavior; phase 3 to the reacquisition; and phase 4 to the second extinction. When animals reached a stable cocaine self-administration behavior (less than $10 \%$ of variability in the number of injections for 5 sequential days) during acquisition and maintenance phase, saline substitution of the first extinction period was carried out. Subsequently, subjects reacquired cocaine self-administration behavior and were maintained self-administering it for 2 weeks. When the animals again reached the stability criterion, a second extinction period started for 10 days. Cocaine maintained robust responding as compared to the responding under saline (first and second extinction phases). The responding during the last 15 days of acquisition phase is very similar to that of the 15 days of reacquisition phase. In both acquisition phases, the number of cocaine injections $/ \mathrm{h}$ was clearly higher than the number of saline injections $/ \mathrm{h}$. In addition, both extinction phases were similar, and the extinction of cocaine self-administration behavior occurred in all the subjects in a very consistent manner. In the days 0 (last day of cocaine IV self-administration), 1,5 , and 10 of the second extinction phase brain animals of the triads $(n=$ 18 in each triad; contingent, $n=6$; noncontingent, $n=6$; saline, $n=6$ ) were removed to be processed for ISHH. See details in the text. Ordinates: Number of cocaine or saline injections per hour in 2-h sessions of cocaine or saline IV self-administration behavior. Abscissas: Consecutive phases and sessions of cocaine or saline IV self-administration behavior. 
both phases of acquisition, the number of cocaine injections/hour was higher than the number of saline injections/hour. Both extinction phases were very similar too, and it is clear from the figure, that extinction occurred in all the subjects in a very consistent manner. This behavioral responding pattern suggests that cocaine was serving as a positive reinforcer in our experimental conditions.

A two-way ANOVA was performed to analyze differences in PENK gene expression during extinction of cocaine self-administration behavior considering the type of cocaine administration and brain region as independent variables. There was a significant main effect of type of administration $(\mathrm{F}(2,17)=107.69, p<.00001)$, brain region $(\mathrm{F}(5,17)=461.90, p<.00001)$, and type of administration $\times$ brain region interaction $(F(10,17)=$ $18,71, p<.00001$ ) on PENK gene expression during extinction of cocaine self-administration behavior.

An over-all view of time course effects of extinction of cocaine self-administration on PENK mRNA levels is shown in Figure 2. Extinction from cocaine self-admin- istration produces a significant increase of PENK mRNA levels in CONT and NONCONT animals in the ST, Acc, TU, and Pir when compared with each corresponding saline group. By contrast, in the VMN and Ce, extinction from cocaine self-administration causes a reduction of PENK mRNA levels in the CONT group with respect to saline or to NONCONT group. No statistical differences were found between the different time points of extinction of cocaine self-administration in the saline group of all brain regions examined.

The detailed one-way ANOVA analysis revealed that PENK mRNA levels in the ST are different in the last day of self-administration session (DAY 0) and during the days of extinction period (DAY 1, DAY 5, and DAY 10). PENK mRNA levels in both cocaine groups significantly increased when compared to SALINE group in DAY $0(\mathrm{~F}(2,12)=12.8, p<.0011)$, DAY 1 $(\mathrm{F}(2,13)=21.12, p<.0001)$, DAY $5(\mathrm{~F}(2,13)=45.2, p=$ $.0001)$, and DAY $10(\mathrm{~F}(2,13)=48.0, p<.0001)$ of our study. No statistical differences were found between CONT and NONCONT groups.

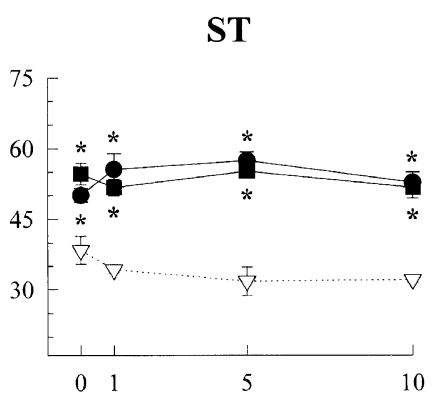

Tu

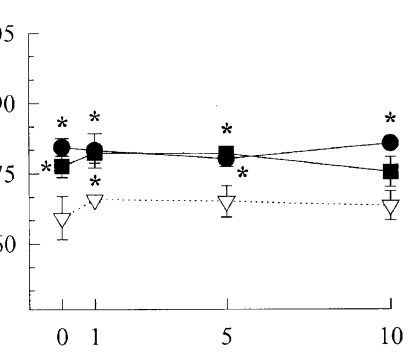

VMN

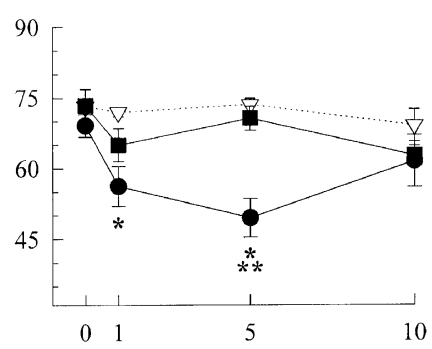

NAcc
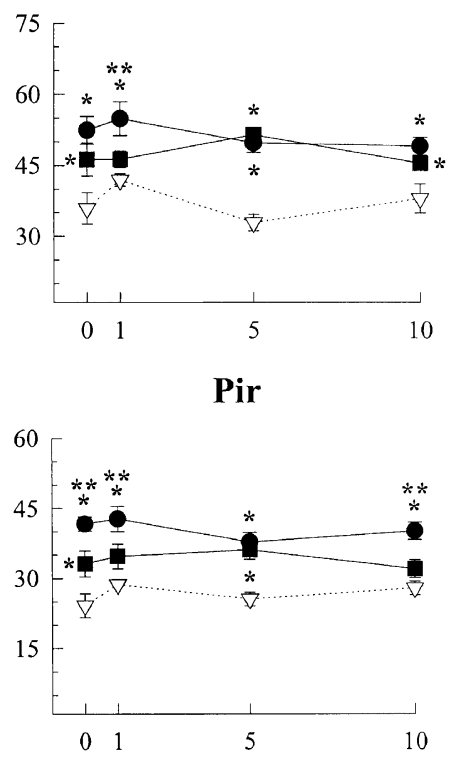

Ce

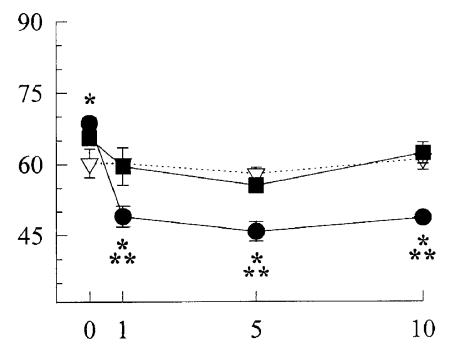

Figure 2. Time course effects of extinction of cocaine self-administration on PENK mRNA levels in caudate putamen (ST), nucleus accumbens (Acc), olfactory tubercle $(\mathrm{Tu})$, piriform cortex (Pir), ventromedial hypothalamic nucleus $(\mathrm{VMN})$, and central nucleus of the amygdala (Ce) in the rat brain of SALINE, CONTINGENT, and NONCONTINGENT groups. Experimental design has been described in Figure 1 and in the Material and Methods section. Symbols represent the means and vertical lines \pm 1 SEM of PENK mRNA levels (arbitrary units of optical density) in 4-6 rats. ${ }^{*}$, values from CONTINGENT or NONCONTINGENT animals that are significantly different $(p<.05)$ from SALINE group. ${ }^{* *}$, values from CONTINGENT animals that are significantly different $(p<.05)$ from NONCONTINGENT group. 
The levels of PENK mRNA in Acc of the three groups differed during the extinction of cocaine selfadministration. PENK mRNA levels in the CONT group were significantly higher than NONCONT and SALINE groups on DAY $1(\mathrm{~F}(2,11)=8.40, p<.0061)$ of extinction. Both cocaine groups also showed higher PENK mRNA levels than SALINE on DAY $0(\mathrm{~F}(2,12)=$ $6.52, p<.0121)$, DAY $5(\mathrm{~F}(2,13)=31.7, p<.0001)$, and DAY 10 of extinction period $(\mathrm{F}(2,13)=6.87, p<.0092)$. No statistical differences were found between NONCONT and SALINE groups on DAY 1 of extinction.

The levels of PENK mRNA in the Tu region of both cocaine groups were significantly higher than SALINE group across all the days of extinction DAY $0(\mathrm{~F}(2,12)=$ 6.01, $p<.0155)$, DAY $1(\mathrm{~F}(2,13)=4.74, p<.0284)$, DAY $5(\mathrm{~F}(2,14)=6.43, p<.0105)$, DAY $10(\mathrm{~F}(2,11)=6.69, p<$ .0126), although no differences were found between cocaine groups.

In the Pir region, PENK mRNA levels in both cocaine groups were higher than in SALINE group DAY 0 $(\mathrm{F}(2,13)=12.10, p<.0011)$, DAY $1(\mathrm{~F}(2,13)=9.64, p<$ $.0027)$, DAY $5(\mathrm{~F}(2,15)=12.35, p<.0007)$, and DAY 10 $(\mathrm{F}(2,15)=12.44, p<.0007)$. In addition, the levels of PENK mRNA in the CONT group were significantly higher than those found in the NONCONT group on all days of extinction in this brain region.

As mentioned previously, PENK mRNA levels in ST, $\mathrm{Acc}, \mathrm{Tu}$, and Pir increased during the extinction of cocaine self-administration. However, in the VMN and $\mathrm{Ce}$, the results revealed a significant decrease in PENK mRNA levels in CONT group when compared to NONCONT and SALINE groups. Indeed, PENK mRNA levels in the VMN of the hypothalamus were lower on DAY $1(\mathrm{~F}(2,9)=5.12, p<.032)$ and DAY 5 $(\mathrm{F}(2,10)=20.03, p<.0003)$ of extinction of CONT group, as compared to NONCONT and SALINE groups. No differences were found between CONT on DAY 0 or DAY 10 and NONCONT or SALINE groups, respectively. Similarly, in the Ce region mRNA levels markedly decreased in the CONT group across all the days of extinction, as compared to the levels of NONCONT and SALINE groups DAY $0(\mathrm{~F}(2,15)=4.23, p<$ $.034)$, DAY $1(\mathrm{~F}(2,12)=5.77, p<.017)$, DAY $5(\mathrm{~F}(2,12)=$ $18.78, p<.0002)$, and DAY $10(\mathrm{~F}(2,12)=16.32, p<$ .0004). There were not statistically significant differences between NONCONT and SALINE groups.

Figure 3 shows representative autoradiograms of the groups SALINE, CONT, and NONCONT used to ana-

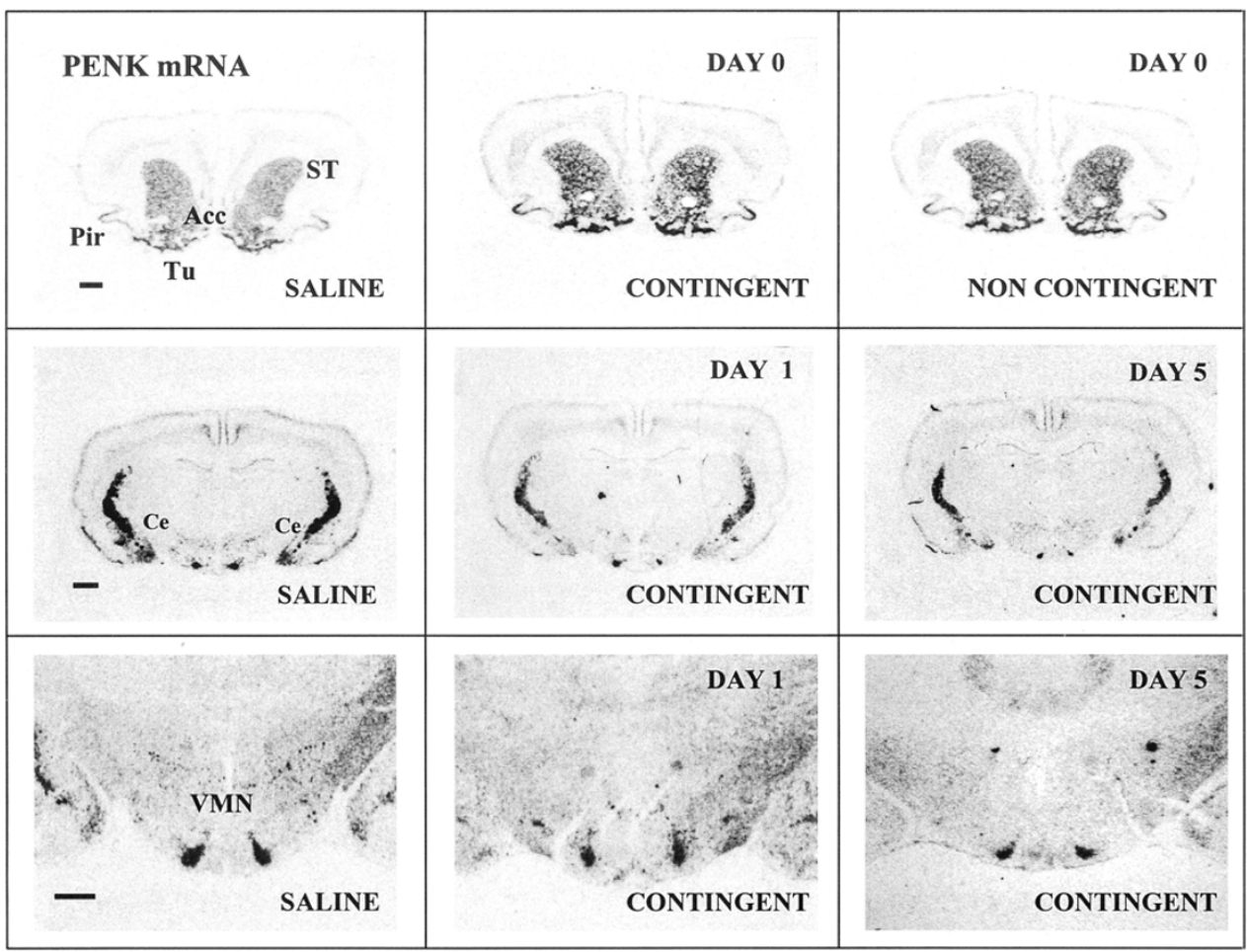

Figure 3. Representative autoradiograms of coronal brain sections at the levels caudate-putamen (ST), nucleus accumbens $(\mathrm{Acc})$, olfactory tubercle (Tu), piriform cortex (Pir), ventromedial hypothalamic nucleus (VMN), and central nucleus of the amygdala (Ce) of the time course effects of extinction of cocaine self-administration on PENK mRNA levels in SALINE, CONTINGENT, and NONCONTINGENT groups. Slides were apposed to film (Kodak, Biomax, MR-1) 3 days for ST, Acc, $\mathrm{Tu}$, and Pir, 7 days for VMN, and 14 days for Ce. Experimental design was as indicated in Figure 1 and in the Material and Methods section. Bar represents $1 \mathrm{~mm}$. 
lyze PENK mRNA levels in the ST, Acc, Pir, Tu, Ce, and VMN after the extinction of cocaine self-administration. In the top row, autoradiograms corresponding to CONT and NONCONT animals in DAY 0 presented a higher intensity in the hybridization signal in ST, Acc, TU, and Pir than the one corresponding to the SALINE group. In contrast, in the middle and bottom rows of Figure 3, it is clear that the hybridization signal in Ce and VMN in CONT animals of DAY 5 is lower than in the SALINE group. The optical densities of the hybridization signal in these autoradiograms have been measured, and the values are similar to mean values of their respective experimental groups.

\section{DISCUSSION}

In this work, in situ hybridization was used to study the effect of long- term cocaine self-administration and its extinction on PENK gene expression in caudate putamen (ST), nucleus accumbens (Acc), olfactory tubercle $(\mathrm{Tu})$, piriform cortex (Pir), central nucleus of amygdala (Ce), and ventromedial hypothalamic nucleus (VMN). The magnitude and significance of the changes in PENK gene expression found in this study depend upon the brain region examined and the type of drug administration (contingent, noncontingent, and saline). Both types of cocaine administration, contingent and noncontingent, increased the expression level of PENK mRNA either on the last day of cocaine self-administration or during the extinction in all the brain regions examined when compared to saline group, except in VMN and Ce nuclei, where a significant decrease was found in contingent animals, as compared to noncontingent and saline groups. In the VMN, the decrease in PENK gene expression returned to noncontingent and saline values 10 days after the extinction of cocaine selfadministration behavior; whereas, in the $\mathrm{Ce}$, the decrease is maintained for the whole 10-day period of extinction. The maintained effects found in PENK gene expression in our study do not suggest a response to short-term compensatory adaptations in brain function after cessation of cocaine self-administration. Interestingly, our results showed an important additional difference in PENK gene expression in some brain regions, depending upon the type of cocaine administration. Although PENK mRNA levels in both cocaine groups were different from those found in the saline group in most of the brain regions examined, with the exception of VMN, the changes persisted mainly in the cocaine contingent administration group 10 days after extinction. These results suggest that an interaction between environmental stimuli and the pharmacological action of cocaine during drug self-administration and its extinction may represent an important variable in the regulation of cocaine action on PENK gene expression.
Our data are not in agreement with those found by others (Branch et al. 1992; Spangler et al. 1997), reporting that 14 days of repeated noncontingent cocaine administration in a bingeing model produced no alterations in PENK mRNA levels. The differences in the results found between both studies underscore the importance of the pattern, dose, route, and time course of cocaine administration on PENK gene expression. In contrast, different modes of cocaine administration or self-administration (Branch et al. 1992; Spangler et al. 1993, 1997) result in similar increases in prodynorphin gene expression in the brain, suggesting that cocaine actions on prodynorphin systems seem more independent of environmental conditions or type of drug administration.

Several of the brain regions included in this study have been proposed as elements of a rewarding circuitry in the mesocorticolimbic dopaminergic system (Koob and Bloom 1988). Ascending monoaminergic projections of the $\mathrm{A}_{10}$ dopamine neurons include the nucleus accumbens, the prefrontal cortex, the cingulate, entorhinal, and piriform cortices, the medial part of the lateral septum, the interstitial nucleus of the stria terminalis, the olfactory tubercle, the anterior medial part of the caudate nucleus, and the amygdaloid complex (Versteeg et al.1976; Fallon and Moore 1978; Moore and Bloom 1978; Simon et al.1979). With the exception of the hypothalamic VMN, all the forebrain regions examined in the present study belong to the hypothesized rewarding circuitry and exhibit modifications in PENK gene expression during cocaine self-administration and its extinction. In addition, the decrease of PENK gene expression found in the present study may play a relevant role in cocaine withdrawal. It has been shown that cocaine self-administered animals exhibit behavioral symptoms upon withdrawal similar to the anxiogenic effects upon exposure to stress (Carroll and Lac 1987; Kleven and Woolverton 1991). Furthermore, PENK mRNA levels in the VMN may be altered after the effects of acute and chronic stress (García-García et al. 1998). Thus, it is possible that the decrease in PENK mRNA content in VMN found in our study represents a response to stress during early cocaine withdrawal phases.

It is particularly interesting to note the persistent decrease in PENK gene expression found in Ce. This nucleus receives the densest dopaminergic innervation arising from the ventral tegmental area to the amygdaloid complex (Fallon and Ciofi 1992), and it is thought to play a role in the modulation of the reinforcing and discriminative stimulus properties of cocaine (Caine et al. 1995; Hurd et al. 1997; Callahan et al. 1995). In addition, it represents an important part of the "extended amygdala," a proposed forebrain continuum bordered by the central nucleus of the amygdala and the shell of the nucleus accumbens, which includes portions of the substantia innominata and bed nucleus of stria terminalis (Alheid and Heimer 1988). Several animal studies 
have suggested the "extended amygdala" as a neural substrate for the behavioral effects of self-administered cocaine (Robledo and Koob 1993; Caine and Koob 1994; Hurd et al. 1997; McGregor and Roberts 1993; Robbins et al. 1989; Robledo et al. 1996). In humans, recent evidence from brain-imaging studies suggest a role for dopamine-rich brain regions, including the nucleus accumbens and amygdala, in cocaine craving (Grant et al. 1996; Breiter et al. 1997; Childress et al. 1999). Along this line, considering the particular conditions of this work, it is tempting to speculate that, in addition to previously documented inhibition of mesocorticolimbic activity (Rossetti et al. 1992; Kuhar and Pilotte 1996), a decrease in proenkephalin gene expression in the Ce may represent a possible mechanism mediating in cocaine withdrawal states.

In conclusion, our data provide evidence of longlasting neuroadaptative changes in proenkephalin gene expression after long-term contingent cocaine administration and its extinction in forebrain regions involved in reinforcing properties of psychostimulants. Although the relevance of changes in PENK mRNA levels elicited by cocaine self-administration and its extinction awaits further analysis of complementary changes in receptor function, the present results are in accordance with other studies showing that chronic cocaine administration produces long-lasting neuroadaptations in gene expression, especially in dopamine terminal fields (Hope et al. 1994; Moratalla et al. 1996; Cha et al. 1997). Long-lasting behavioral alterations exist associated with cocaine addiction, including the development of paranoia and drug craving (Satel and Edell 1991; Childress et al. 1999). In this sense, research on alterations in gene expression produced by long-term cocaine selfadministration and its extinction could be a useful approach to determine neuroadaptative changes involved in cocaine withdrawal states.

\section{ACKNOWLEDGMENTS}

The authors are grateful to R. Ferrado for technical assistance. This research was supported by DGESIC Grants PB93-0290 and PM97-0027 to the UNED group. Cocaine chlorhydrate was kindly provided by Dirección General de Estupefacientes (Spain).

\section{REFERENCES}

Alheid GF, Heimer L (1988): New perspectives in basal forebrain organization of special relevance for neuropsychiatric disorders: The striatopallidal, amygdaloid, and corticopetal components of the substantia innominata. Neuroscience 27:1-39

Ambrosio E, Tella SR, Goldberg SR, Schindler CW, Erzouki H, Elmer GI (1996): Cardiovascular effects of cocaine during operant cocaine self-administration. Eur J Pharmacol 315:43-51

Branch AD, Unterwald EM, Lee SE, Kreek MJ (1992): Quantitation of proenkephalin mRNA levels in brain regions from male Fischer rats following chronic cocaine treatment using a recently developed solution hybridization procedure. Mol Brain Res 14:231-238

Breiter HC, Gollub RL, Weisskoff RM, Kennedy DN, Makris N, Berke JD, Goodman JM, Kantor HL, Gastfriend DR, Riorden JP, Mathew RT, Rosen Br, Hyman SE (1997): Acute effects of cocaine on human brain activity and emotion. Neuron 19:591-611

Caine SB, Koob GF (1994): Effects of mesolimbic dopamine depletion on responding maintained by cocaine and food. J Exp Anal Behav 61:213-221

Caine SB, Heinrichs SC, Coffin VL, Koob GF (1995): Effects of the dopamine D-1 antagonist SCH 23390 microinjected into the nucleus accumbens, amygdala, or striatum on cocaine self-administration in the rat. Brain Res 692:47-56

Callahan PM, Bryan SK, Cumming KA (1995): Discriminative stimulus effects of cocaine: Antagonism by dopamine D1 receptor blockade in the amygdala. Pharmacol Biochem Behav 51:759-766

Carroll ME, Lac ST (1987): Cocaine withdrawal produces behavioral disruption in rats. Life Sci 40:183-190

Cha X-Y, Pierce RC, Kalivas PW, Mackler SA (1997): NAC-1, a rat brain mRNA, is increased in the nucleus accumbens three weeks after chronic cocaine self-administration. J Neurosci 17:6864-6871

Childress AR, Mozley PD, McElgin W, Fitzgerald J, Reivich M, O'Brien CP (1999): Limbic activation during cueinduced cocaine craving. Am J Psychiat 156:11-18

Daunais JB, Roberts DCS, McGinty JF (1993): Cocaine selfadministration increases preprodynorphin, but not cfos, mRNA in rat striatum. Neuroreport 4:543-546

Daunais JB, McGinty JF (1995): Cocaine binges differentially alter striatal preprodynorphin and zif/268 mRNAs. Mol Brain Res 29:201-210

Daunais JB, Nader MA, Porrino LJ (1997): Long-term cocaine self-administration decreases striatal preproenkephalin mRNA in rhesus monkeys. Pharmacol Biochem Behav 57:471-475

Dworkin SI, Porrino LJ, Smith JE (1992): Importance of behavioral controls in the analysis of ongoing events. NIDA Research Monograph 124. US Government Printing Office, Washington, DC, pp 173-188

Dworkin SI, Co C, Smith JE (1995): Rat brain neurotransmitter turnover rates altered during withdrawal from chronic cocaine administration. Brain Res 682:116-126

Ehrman RN, Robbins SJ, Childress AR, O'Brien CP (1992): Conditioned responses to cocaine-related stimuli in cocaine abuse patients. Psychopharmacology 107:523529

Fallon JH, Moore RY (1978): Catecholamine innervation of basal forebrain. IV. Topography of the dopamine projection to the basal forebrain and striatum. J Comp Neurol 180:545-580

Fallon JH, Ciofi P (1992): Distribution of monoamines within the amygdala. In Aggleton JP(ed), The Amygdala: Neu- 
robiological Aspects of Emotion, Memory, and Mental Dysfunction. New York, Wiley-Liss, pp 97-114

García-García L, Llewellyn-Jones V, Fernandez Fernandez I, Fuentes JA, Manzanares J (1998): Acute and repeated ECS treatment increases CRF, POMC, and PENK gene expression in selected regions of the rat hypothalamus. Neuroreport 9:73-77

Grant S, London ED, Newlin DB, Villemagne VL, Liu X, Cotoreggi C, Phillips RL, Kimes AS, Margolin A (1996): Activation of memory circuits during cue-elicited cocaine craving. Proc Natl Acad Sci USA 93:1204012045

Hadfield MG, Mott DE, Ismay JA (1980): Cocaine: Effect of in vivo administration on synaptosomal uptake of norepinephrine. Biochem Pharmacol 29:1861-1863

Hammer RP Jr (1989): Cocaine alters opiate receptor binding in critical brain reward regions. Synapse 3:55-60

Harlan RE, Shivers BD, Romano GJ, Howells RD, Pfaff DW (1987): Localization of preproenkephalin mRNA in the rat brain and spinal cord by in situ hybridization. J Comp Neurol 258:159-184

Heikkila RE, Orlansky H, Cohen G (1975): Studies of the distinction between uptake inhibition and release of $\left[{ }^{3} \mathrm{H}\right]$ dopamine in rat brain tissue slices. Biochem Pharmacol 24:847-852

Hemby SE, Co C, Koves TR, Smith JE, Dworkin SJ (1997): Differences in extracellular dopamine concentration in the nucleus accumbens during response - Independent cocaine administration in the rat. Psychopharmacology 133:7-16

Hope BT, Nye HE, Kelz MB, Self DW, Iadarola MJ, Nakabeppu Y, Duman RS, Nestler EJ (1994): Induction of a long lasting AP-1 complex composed of altered Fos-like proteins in brain by chronic cocaine and other chronic treatments. Neuron 13:1235-1244

Hurd YL, Brown EE, Finlay JM, Fibiger HC, Gerfen CR (1992): Cocaine self-administration differentially alters mRNA expression of striatal peptides. Mol Brain Res 13:165-170

Hurd YL, Herkenham M (1993): Molecular alterations in the neostriatum of human cocaine addicts. Synapse 13:357369

Hurd YL, McGregor A, Ponten M (1997): In vivo amygdala dopamine levels modulate cocaine self-administration behavior: Dopamine D1 receptor involvement. Eur J Neurosci 9:2541-2548

Izenwasser S (1998): Basic pharmacological mechanisms of cocaine. In Higgins ST, Katz JL (eds), Cocaine Abuse. Behavior, Pharmacology, and Applications. San Diego, CA, Academic Press, pp 1-20

Kleven MS, Woolverton WL (1991): Effects of continuous cocaine administration on scheduled-controlled behavior in rhesus monkeys. Behav Pharmacol 2:471-480

Koob GF, Bloom FE (1988): Cellular and molecular mechanisms of drug dependence. Science 242:715-722

Kuhar MJ, Ritz MC, Boja JW (1991): The dopamine hypothesis of the reinforcing properties of cocaine. Trends in Neurosci 14:299-302

Kuhar MJ, Pilotte NS (1996): Neurochemical changes in cocaine withdrawal. Trends Pharmacol Sci 17:260-264
McGregor A, Roberts DCS (1993): Dopaminergic antagonism within the nucleus accumbens or the amygdala produces differential effects on intravenous cocaine self-administration under fixed and progressive ratio schedules of reinforcement. Brain Res 624:245-252

Moldow RL, Fischman AJ (1987): Cocaine-induced secretion of ACTH, beta-endorphin, and corticosterone. Peptides $8: 819-822$

Moratalla R, Elibol B, Vallejo M, Gaybriel AM (1996): Network-level changes in expression of inducible fos-jun proteins in the striatum during chronic cocaine treatment and withdrawal. Neuron 17:147-156

Moore RY, Bloom FE (1978): Central catecholamine neuron systems: Anatomy and physiology of the dopamine systems. Ann Rev Neurosci 1:129-160

Nestler EJ (1993): Cellular responses to chronic treatment with drugs of abuse. Crit Rev Neurobiol 7:23-39

Paxinos G, Watson C (1986): The Rat Brain in Stereotaxic Coordinates. San Diego, CA, Academic Press

Pierce RC, Kalivas PW (1997): A circuitry model of the expression of behavioral sensitization to amphetaminelike psychostimulants. Brain Res Rev 25:192-216

Ritz MC, Lamb RJ, Goldberg SR, Kuhar MJ (1987): Cocaine receptors on dopamine transporters are related to selfadministration of cocaine. Science 237:1219-1223

Robbins TW, Cador M, Taylor JR, Everitt BJ (1989): Limbicstriatal interactions in reward-related processed. Neurosci Biobehav Rev 13:155-162

Robledo P, Page K, Weissenborn R, Robbins TW, Everitt BJ (1996): Effects of excitotoxic lesions of central amygdaloid nucleus on the potentiation of reward-related stimuli by intra-accumbens amphetamine. Behav Neurosci 110:981-990

Robledo P, Koob GF (1993): Two discrete nucleus accumbens projections areas differentially mediate cocaine self-administration in the rat. Behav Brain Res 55:159166

Rocha BA, Fumagalli F, Gainetdinov RR, Jones SR, Ator R, Giros B (1998): Cocaine self-administration in dopamine transporter knockout mice. Nature Neurosci 1:132-137

Ross SB, Renyi AL (1969): Inhibition of the uptake of tritiated 5-hydroxytryptamine in brain tissue. Eur J Pharmacol 7:270-277

Rossetti ZL, Hmaidan Y, Gessa GL (1992): Marked inhibition of mesolimbic dopamine release: A common feature of ethanol, morphine, cocaine, and amphetamine abstinence in rats. Eur J Pharmacol 221:227-234

Satel SL, Edell WS (1991): Cocaine-induced paranoia and psychosis proneness. Am J Psychiat 148:1708-1711

Simon H, Le Moal M, Calas A (1979): Efferents and afferents of the ventral tegmental A10 region studied after local injection of $\left[{ }^{3} \mathrm{H}\right]$ leucine and horseradish peroxidase. Brain Res 178:17-23

Sivam SP (1989): Cocaine selectively increases striatonigral dynorphin levels by a dopaminergic mechanism. J Pharmacol Exp Ther 250:818-824

Smiley PL, Johnson M, Bush L, Gibb JW, Hanson GR (1990): Effects of cocaine on extrapyramidal and limbic dynorphin systems. J Pharmacol Exp Ther 253:938-943 
Smith JE, Dworkin SI (1986): Neurobiological substrates of drug self-administration. In Brown RM, Clouet D, (eds), Opiate Receptor Subtypes and Brain Function. National Institute on Drug Abuse Research Monograph 71, pp 127-145

Spanagel R, Weiss F (1999): The dopamine hypothesis of reward: Past and current status. Trends Neurosci 22:521-527

Spangler R, Unterwald EM, Kreek MJ (1993): “Binge" cocaine administration induces a sustained increase of prodynorphin mRNA in rat caudate putamen. Mol Brain Res 19:323-327

Spangler R, Ho A, Zhou Y, Maggos CE, Yuferov V, Kreek MJ (1996): Regulation of kappa opioid receptor mRNA in the rat brain by binge pattern cocaine administration and correlation with preprodynorphin mRNA. Mol Brain Res 38:71-76

Spangler R, Zhou Y, Maggos CE, Schlussman SD, Ho A, Kreek MJ (1997): Prodynorphin, proenkephalin, and kappa opioid receptor mRNA responses to acute "binge" cocaine. Mol Brain Res 44:139-142

Székely JI (1994): Elements of a uniform brain reward circuitry. In Székely JI (ed), Opioids Peptides in Substance Abuse. Boca Raton, FL, CRC Press, pp 109-126
Unterwald EM, Horne-King J, Kreek MJ (1992): Chronic cocaine alters brain $\mathrm{mu}$ opioid receptors. Brain Res 584:314-318

Unterwald EM, Rubenfeld JM, Kreek MJ (1994): Repeated cocaine administration upregulates $\kappa$ and $\mu$ but not $\delta$ opioid receptors. Neuroreport 5:1613-1616

Versteeg DMG, Van der Gugten J, De Jong W, Palkovits M (1976): Regional concentrations of noradrenaline and dopamine in the rat brain. Brain Res 113:563-569

Wilson JM, Nobrega JN, Corrigal WA, Coen KM, Kish SJ (1994): Amygdala dopamine levels are markedly elevated after self- but not passive- administration of cocaine. Brain Res 668:39-45

White FJ, Xiu Y-H, Henry DJ, Zhang X -F (1995): Neurophysiological alterations in the mesocorticolimbic dopamine system during repeated cocaine administration. In Hammer RP Jr (ed), The Neurobiology of Cocaine. Boca Raton, FL, CRC Press, pp 99-120

Young III S, Bonner T, Brann M (1986): Mesencephalic dopamine neurons regulate the expression of neuropeptide mRNAs in the rat forebrain. Proc Natl Acad Sci USA 83:9827-9831 